Research Article

\title{
The Protective Effect of the Total Flavonoids of Abelmoschus esculentus L. Flowers on Transient Cerebral Ischemia-Reperfusion Injury Is due to Activation of the Nrf2-ARE Pathway
}

\author{
Yang Luo, ${ }^{1}$ Hong-Xin Cui $\mathbb{D}^{2},{ }^{2}$ An Jia, ${ }^{3}$ Shan-Shan Jia, ${ }^{1}$ and Ke Yuan $\mathbb{D}^{1,4}$ \\ ${ }^{1}$ Zhejiang Agriculture and Forestry University, Lin'an 311300, China \\ ${ }^{2}$ College of Pharmacy, Henan University of Chinese Medicine, Zhengzhou 450046, China \\ ${ }^{3}$ College of Medicine, Huanghe $S$ \& $T$ University, Zhengzhou 450063, China \\ ${ }^{4}$ Jiyang College, Zhejiang Agriculture and Forestry University, Zhuji 311800, China
}

Correspondence should be addressed to Ke Yuan; yuan_ke001@126.com

Received 1 April 2018; Revised 14 June 2018; Accepted 23 June 2018; Published 5 August 2018

Academic Editor: Germán Gil

Copyright ( 2018 Yang Luo et al. This is an open access article distributed under the Creative Commons Attribution License, which permits unrestricted use, distribution, and reproduction in any medium, provided the original work is properly cited.

\begin{abstract}
Abelmoschus esculentus L. has favorable nutritional/medicinal features. We found the content of total flavonoids in flower extract to be the highest $(788.56 \mathrm{mg} / \mathrm{g})$ of all the different parts of $A$. esculentus; according to high-performance liquid chromatography, the quercetin-3-O-[ $\beta$-D-glu- $(1 \rightarrow 6)]-\beta$-D-glucopyranoside content was $122.13 \mathrm{mg} / \mathrm{g}$. Protective effects of an extract of the total flavonoids of $A$. esculentus flowers (AFF) on transient cerebral ischemia-reperfusion injury (TCI-RI) were investigated. Compared with the model group, mice treated with AFF $(300 \mathrm{mg} / \mathrm{kg})$ for 7 days showed significantly reduced neurologic deficits, infarct area, and histologic changes in brain tissue, accompanied by increased contents of superoxide dismutase, whereas contents of nitric oxide and malondialdehyde decreased. AFF upregulated the expression of Nrf2, HO-1, and NQO1. These data suggest that AFF protects against TCI-RI by scavenging free radicals and activating the Nrf2-ARE pathway.
\end{abstract}

\section{Introduction}

Ischemic cardiovascular disease (also known as "ischemic stroke") is the third leading cause of death and disability worldwide [1]. The number of patients suffering from cerebral ischemic disease worldwide has increased by 2 million per year, and the morbidity associated with this disease can affect young people [2].

At present, several of the synthetic drugs used for the treatment of transient ischemic attack have side effects. "Natural" medicines have good curative effects and few side effects. In addition, cerebral ischemic disease is an emergency, difficult to predict, and its pathogenesis is complex [3]. During reperfusion after a transient ischemic attack, a combination of oxidative stress and release of excitatory neurotransmitters causes irreversible damage, inflammation, and even apoptosis of nerve cells $[4,5]$. Therefore, searching for natural products for protection and treatment of transient cerebral ischemia-reperfusion injury (TCI-RI) and exploring their mechanism of action are a rational approach.

Nuclear factor-E2-related factor 2 (Nrf2) is a key regulator of defense against endogenous antioxidants. Most genes encoding antioxidant enzymes have antioxidant response element (ARE) sequences in their promoter regions. Studies have demonstrated that the activation of the Nrf2-ARE pathway contributes to neuroprotection following ischemic injury [6-8].

Abelmoschus esculentus L. commonly known as "lady's fingers," "okra," or "bhindi" is an important vegetable crop cultivated in many countries $[9,10]$. The fruits are beneficial to the digestive and immune systems due to the high content of glycoproteins and microelements and are used as food additives because of their antigastric acid, antifatigue, antioxidation, and anti-inflammation properties [11]. The seeds of 
A. esculentus are a good source of many high-quality proteins and unsaturated fatty acids and have anticancer, antidiabetes mellitus, and antihyperlipidemia properties [12-14]. The flowering period of $A$. esculentus is long, and the yield is high, but $A$. esculentus flowers wither rapidly, so they tend not to be studied. A. esculentus flowers are good sources of flavonoids and polysaccharides and are involved in modulation of the immune system [15]. However, studies on the protective effects of an extract of the total flavonoids of A. esculentus flowers (AFF) on TCI-RI and its mechanism of action are lacking.

Therefore, we explore the protective effect of AFF on TCI-RI and its potential mechanism.

\section{Material and Methods}

2.1. Materials. The reference samples of quercetin-3-O-[ $\beta$ D-glu- $(1 \rightarrow 6)]$ - $\beta$-D-glucopyranoside (AFG-1), quercetin3 -O-[ $\beta$-D-xyl- $(1 \rightarrow 2)]-\beta$-D-glucopyranoside (AFG- 2 ), and quercetin- $4^{\prime \prime}$-O-methy-3-O- $\beta$-D-glucopyranoside (AFG-3) at a purity of $>98 \%$ were separated by our research team [16]. Rutin reference sample was purchased from China Pharmaceutical and Biological Products Testing Institute. A. esculentus flower, fruit, and seed samples were picked up in vegetable test base of Zhejiang Agricultural and Forestry University in 2016. Nitric oxide (NO), malondialdehyde (MDA), superoxide dismutase (SOD), and Coomassie Brilliant Blue kit were purchased from Nanjing Jiancheng Biological Technology Co. Ltd. Antibodies against Nrf2, heme oxygenase-1 (HO-1), NAD(P)H:quinone oxidoreductase-1 (NQO1), and $\beta$-actin were purchased from Wanlei Biological Technology Co. Ltd. Chloral hydrate was purchased from Zhejiang Academy of Medical Sciences. All the reagents were of analytical or HPLC grade.

2.2. Extraction and Purification of Total Flavonoids from A. esculentus. Fresh samples of the flowers, fruits, and seeds of A. esculentus were weighed $(10 \mathrm{~kg})$, dried at $40^{\circ} \mathrm{C}$, crushed, and passed through a 60 -mesh sieve. These powders were reextracted by ultrasonication thrice with $70 \%$ ethanol: water at a $1: 30$ ratio $(w: v)$ for $30 \mathrm{~min}$ each at room temperature. The extracts were combined and concentrated into a paste using a rotary evaporator. Then, the concentrated solution was extracted with ethyl acetate to remove fat-soluble components. The remaining extract was added to a column with resin (Diaion HP-20, Mitsubishi, Japan). The resin was washed with distilled water to remove proteins, polysaccharides, and other water-soluble impurities. Then, the eluate was collected with $50 \%$ methanol and dried by a rotary evaporator at $50^{\circ} \mathrm{C}$. Powdered extracts of the total flavonoids of the flowers $(258.8 \mathrm{~g})$, fruits $(186.3 \mathrm{~g})$, and seeds $(160.6 \mathrm{~g})$ of A. esculentus were obtained and stored at $4^{\circ} \mathrm{C}$.

2.3. Determination of the Composition of Total Flavonoids in Extracts. Each sample extract (10.0 mg), AFG-1 (31.6 mg), AFG-2 (3.25 mg), AFG-3 (5.08 mg), and rutin (10.0 mg) were dissolved in methanol and made up to $10 \mathrm{~mL}$ to provide samples and standard solutions. We measured the contents of total flavonoids using an $\mathrm{AlCl}_{3}$-colorimetric assay [17]. The absorbance was measured at $510 \mathrm{~nm}$, and the content was expressed as milligram rutin equivalent per gram dry weight (mg RE/g DW). All samples were assayed thrice.

AFG-1, AFG-2, and AFG-3 contents were analyzed on a high-performance liquid chromatography (HPLC) system (2695; Waters, Milford, MA, USA) with a photodiode array detector (2996; Waters) under specific HPLC conditions: SunFire C18 column $(4.6 \mathrm{~mm} \times 250 \mathrm{~mm}, 5.4 \mu \mathrm{m})$, column temperature $=28^{\circ} \mathrm{C}$, flow rate $=0.8 \mathrm{~mL} / \mathrm{min}$, mobile phase $=$ methanol (solvent A) : $0.1 \%$ phosphoric acid water (solvent B), and ratio of gradient elution, 47:53. These solutions were determined at an absorbance of $255.6 \mathrm{~nm}$ with sample feeding of $10 \mu \mathrm{L}$. Identification of unknown peaks was based on comparison of the retention times with those of known standards.

2.4. Animal Experiments. All procedures were approved by the Committee on the Ethics of Animal Experiments at Zhejiang Agriculture and Forestry University (Zhejiang, China).

Male Kunming mice (18-22 g) were purchased from the Animal Experiment Center of Zhejiang Academy of Medical Sciences (Zhejiang, China; number SC 2008-3344). Before experimentation, all mice were maintained in a wellventilated environment $\left(23-24^{\circ} \mathrm{C}\right.$; humidity, 56-59\%) with a $12 \mathrm{~h}$ light-dark cycle and had free access to food and water for 1 week.

Mice $(n=75)$ were divided randomly into five groups, normal group (sham operation), model group, as well as high (300 mg/kg), medium (150 mg/kg), and low (75 mg/kg) AFF dose groups. $300 \mathrm{mg} / \mathrm{kg}$ has proven to be safe [18]. Mice in normal and model groups were given an equal volume of water, and in the other groups, the corresponding amounts of AFF were given once daily for 7 days. One hour after the final administration, mice in model and AFF groups were anesthetized (3.5\% chloral hydrate, i.p.) and placed on a mouse fixator. Creation of the TCI-RI model is shown in Figure 1 . The neck was disinfected with $75 \%$ alcohol. A midline incision was made, and skin was separated bluntly to allow exposure of bilateral common carotid arteries. Using an arterial clip, blood flow to bilateral common carotid arteries was blocked for $30 \mathrm{~min}$. Subsequently, the arterial clip was loosened to recover this blood supply and the incision was sutured. In the normal group, bilateral common carotid arteries were not blocked and only suturing of the incision was done. After $24 \mathrm{~h}$ of reperfusion, the neurologic damage was evaluated. Then, 10 survived mice in each group were sacrificed, and their brain tissues were removed rapidly and stored at $20^{\circ} \mathrm{C}$.

2.5. Survival and Neurologic Function Score. After TCI-RI for $24 \mathrm{~h}$, the survival rate in each group was determined as the ratio of the number of survived mice to the total number of mice. An evaluator blinded to the treatment protocol undertook neurologic scoring as described by Longa et al. [19]. The scoring criteria are the following: $0=$ no neurological deficits, 1 = failure to extend contralateral forepaw fully, $2=$ circling to paretic side, $3=$ falling to contralateral side, and $4=$ did not walk spontaneously and has a depressed level of consciousness. 


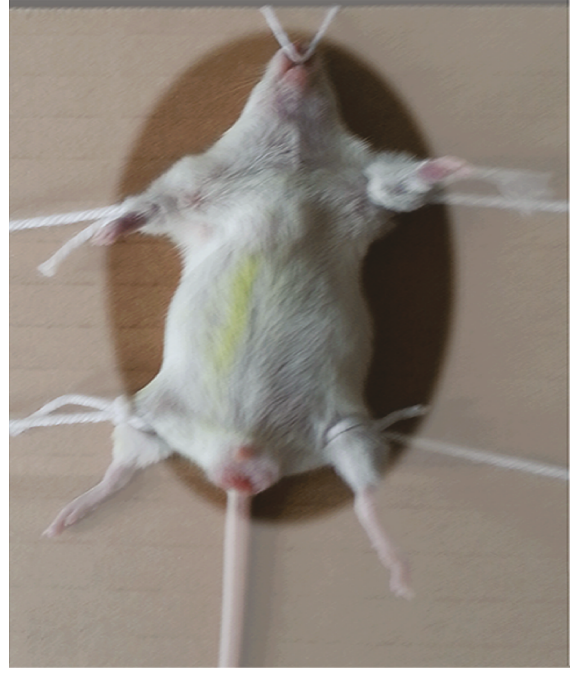

(a)

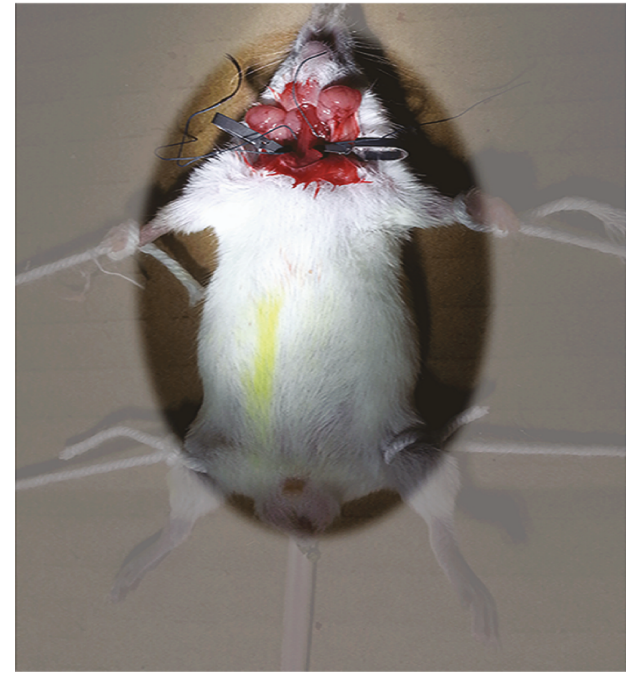

(b)

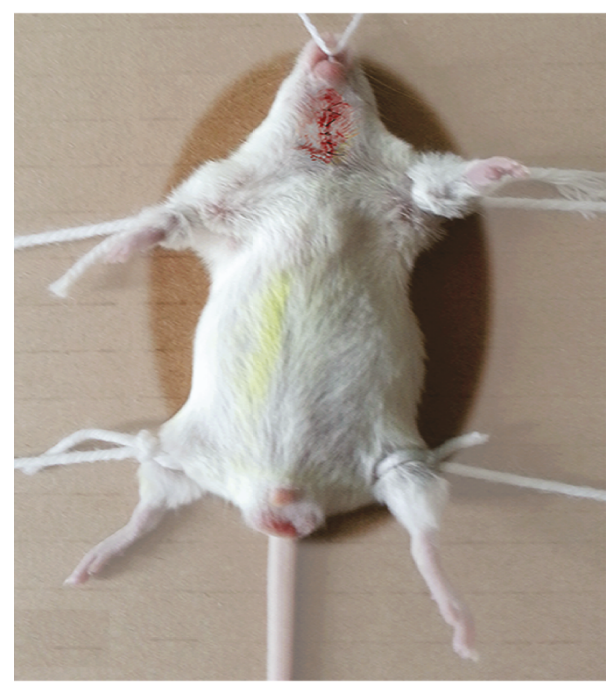

(c)

FIgure 1: The process of TCI-RI operation. (a) The mouse was narcotized and fixed. (b) The middle neck of the mouse was cut, and the bilateral carotid artery was tied with thread and clamped with the arterial clip for $30 \mathrm{~min}$. (c) After removal of the arterial clip and the line, the mouse wound was sutured and the mouse was reperfused for $24 \mathrm{~h}$.

2.6. Evaluation of the Infarct Area. The brain tissues in each group $\left(n_{1}=3\right)$ were obtained in a random manner. Then, the cerebrums were cut into five coronal sections of thickness $2 \mathrm{~mm}$. They were incubated immediately in $2 \%$ 2,3,5-triphenyltetrazolium chloride (TTC) solution at $37^{\circ} \mathrm{C}$ for $30 \mathrm{~min}$ in the dark and fixed in $10 \%$ formalin. After that, the stained slices were photographed using a camera (EOS30, Canon, Japan). The infarct area in each section was calculated using an image analyzer (Image-Pro Plus 6.0). The percentage of the infarct area was calculated using the following formula:

$$
\text { Infarct area }(\%)=\frac{\text { total infarct area }}{\text { total section area }} \times 100 \text {. }
$$

2.7. Histopathology. The whole brain tissues of each group $\left(n_{2}=3\right)$ after reperfusion for $24 \mathrm{~h}$ were fixed with $4 \%$ paraformaldehyde for $24 \mathrm{~h}$, stained with hematoxylin and eosin (H\&E), and then observed with an optical microscope (BX20, Olympus, Tokyo, Japan).

2.8. TUNEL Assay. The whole brain tissues of each group $\left(n_{2}=3\right)$ after reperfusion for $24 \mathrm{~h}$ were fixed with $4 \%$ paraformaldehyde for $24 \mathrm{~h}$, regularly embedded in paraffin, sectioned at a thickness of $4 \mu \mathrm{m}$, deparaffinized, stained with terminal deoxynucleotidyl transferase-mediated (dUTP) nick end labeling (TUNEL) reagents and DAPI solution, washed, and then photographed using a fluorescence microscope (Nikon Eclipse C1, Nikon, Japan). The positive cells (green spots) were identified and counted by an investigator blinded to the grouping. Three mice and 10 regions of the fluorescent images were used to obtain the apoptotic cell data. 
TABLE 1: Results for the determination of three kinds of flavonoid glycosides and total flavonoids in different parts extract of A. esculentus.

\begin{tabular}{lccccc}
\hline Part & $\begin{array}{c}\text { AFG-1 } \\
\text { (content/mg/g DW) }\end{array}$ & $\begin{array}{c}\text { AFG-2 } \\
\text { (content/mg/g DW) }\end{array}$ & $\begin{array}{c}\text { AFG-3 } \\
\text { (content/mg/g DW) }\end{array}$ & $\begin{array}{c}\text { Total flavones } \\
\text { (content/mg/g DW) }\end{array}$ & $\begin{array}{c}\text { Powder yield } \\
\text { Flower }\end{array}$ \\
Seed & 122.13 & 9.54 & 16.86 & 788.56 \\
Fruit & 53.16 & 3.01 & 28.06 & 627.04 & $1.86 \%$ \\
\hline
\end{tabular}

2.9. Biochemical Analyses of Brain Tissue. The brain tissues in each group $\left(\mathrm{n}_{3}=4\right)$ were homogenized with nine-fold physiological saline. The $10 \%$ homogenate was centrifuged at $3000 \mathrm{rpm}$ for $10 \mathrm{~min}$ at room temperature. The $10 \%$ supernatants $(100 \mu \mathrm{L})$ were made into $2 \%$ concentration with cold physiological saline $(400 \mu \mathrm{L})$ to determine the protein content with Coomassie Brilliant Blue kit (standard solution: $0.563 \mathrm{~g} / \mathrm{L}$ embryonic bovine serum BSA). The $10 \%$ supernatants were used to determine the contents of nitric oxide (NO), superoxide dismutase (SOD), and malondialdehyde (MDA) with the commercially available kits, and their results were expressed as equivalent per gram protein concentration.

2.10. Western Blotting. To analyze protein expression, brain tissue homogenates $\left(n_{3}=4\right)$ were centrifuged at $14,000 \mathrm{rpm}$ for $30 \mathrm{~min}$ at $4^{\circ} \mathrm{C}$ to obtain total protein. Protein content was quantified using a bicinchoninic acid protein assay kit. Equal amounts of protein ( $50 \mu \mathrm{g}$ per lane) were resolved on $12 \%$ polyacrylamide gels, transferred to polyvinylidene fluoride (PVDF) membranes (Millipore, Marlborough, MA, USA), and probed with primary antibodies against Nrf2, HO-1, NQO1, and $\beta$-actin. PVDF membranes were washed thrice for $10 \mathrm{~min}$ each and incubated for $2 \mathrm{~h}$ at $4^{\circ} \mathrm{C}$ with horseradish peroxidase-conjugated secondary antibody (anti-rat). Proteins were visualized using an enhanced chemiluminescence detection system (Amersham Pharmacia, Piscataway, NJ, USA).

2.11. Statistical Analysis. Data were analyzed by one-way ANOVA with Duncan's test and intergroup comparison using SPSS statistical software (SPSS 19.0 Inc., Chicago, IL, USA) and expressed as mean \pm standard deviation (SD). $P$ values below 0.05 were considered statistically significant.

\section{Results and Discussion}

3.1. Contents of Total Flavonoids and Flavonoid Glycosides in Different Parts of A. esculentus. The fruits, seeds, roots, stems, leaves, and flowers of $A$. esculentus are used widely as traditional medicines in China because of their anticancer and anti-inflammatory effects [20]. It has been reported that the flowers, fruits, and seeds of $A$. esculentus are good sources of flavonoids and that the total content of flavonoids is different in different parts of $A$. esculentus.

The total content of flavonoids in flower extract was highest in different parts of $A$. esculentus, and the highest amount was $788.56 \mathrm{mg} / \mathrm{g}$ (Table 1). The three flavonoid glycosides, AFG-1, AFG-2 and AFG-3, the structures of which are shown in Figure 2, were the main components in different parts of A. esculentus (Figure 2). In AFF, the AFG-
1 content was $122.13 \mathrm{mg} / \mathrm{g}$. Therefore, the potential protective effect of AFF upon TCI-RI was investigated.

3.2. Effect of AFF on the Survival Rate and Neurologic Damage. Transient cerebral ischemia is associated with high mortality and morbidity. Transient cerebral ischemia changes the cerebral ultrastructure and induces hypoxia and ischemia in the middle cerebral artery, which damages the nervous system $[6,21]$. Only $52.6 \%$ of mice in the model group survived (Table 2). After AFF treatment, the survival rate was improved significantly depending on the AFF dose $(P<0.05)$. According to the observation of behavior and neurologic scores, mice in the normal group (which did not suffer damage to the nervous system) could move normally. The score of the model group was significantly different from that of the normal group $(P<0.01)$; the contralateral forepaw could not be extended forward or circled around, and athletic ability was weakened (neurologic score $=2.8 \pm 0.79$ ). The neurologic scores of the AFF (300 and $150 \mathrm{mg} / \mathrm{kg}$ ) groups were significantly higher than those of the model group $(P<0.01)$, and mice did not fall to one side or suffer dyskinesia.

These results suggested that AFF could protect the nervous system from the effects of cerebral ischemic attack. Studies have shown that flavonoids have antioxidant functions [22]. Yuan et al. found that the total flavonoid extracts of flowers, fruits, leaves, and seeds all have free radical scavenging activity and antioxidant capacity and the free radicals scavenging capacity of AFF is relatively strong in vitro [23]. Neural cells in the brain have been more vulnerable to oxidative stress because they have high oxygen consumption and contain high levels of unsaturated fatty acids, essential prooxidants for lipid peroxidation, and low levels of antioxidant defense capacities [24]. Thereby, AFF scavenged free radicals to protect nerve cells from oxidative damage.

3.3. Effect of AFF on the Cerebral Infarction Area. Transient cerebral ischemia does not necessarily result in disability or death if timely return of oxygen and blood supply is initiated. Most cases of ischemic cardiovascular disease are caused by more severe reperfusion injury due to prolonged ischemia or hypoxia in the brain and heart $[25,26]$. In patients with cerebral infarction, the infarct area of the middle cerebral arterial trunk is $82.12 \%$ [27]. Therefore, we used a method based on occlusion of the internal carotid artery to cause TCI-RI in mice, which results in symptoms similar to those of cerebral ischemia in humans.

Brain tissues were stained by TTC (Figures 3(a) and $3(\mathrm{~b})$ ), with red regions indicated normal tissue and white regions representing infarction. Compared with the normal 
<smiles>O=c1c(OC2OC3(CO)OC(O)C(O)C(O3)C2O)c(-c2ccc(O)c(O)c2)oc2cc(O)cc(O)c12</smiles>

AFG1<smiles>O=c1c(OC2OC3C4OC(CO)C(O)C(O)(C4O)C3O2)c(-c2ccc(O)c(O)c2)oc2cc(O)cc(O)c12</smiles>

AFG2<smiles></smiles>

AFG3

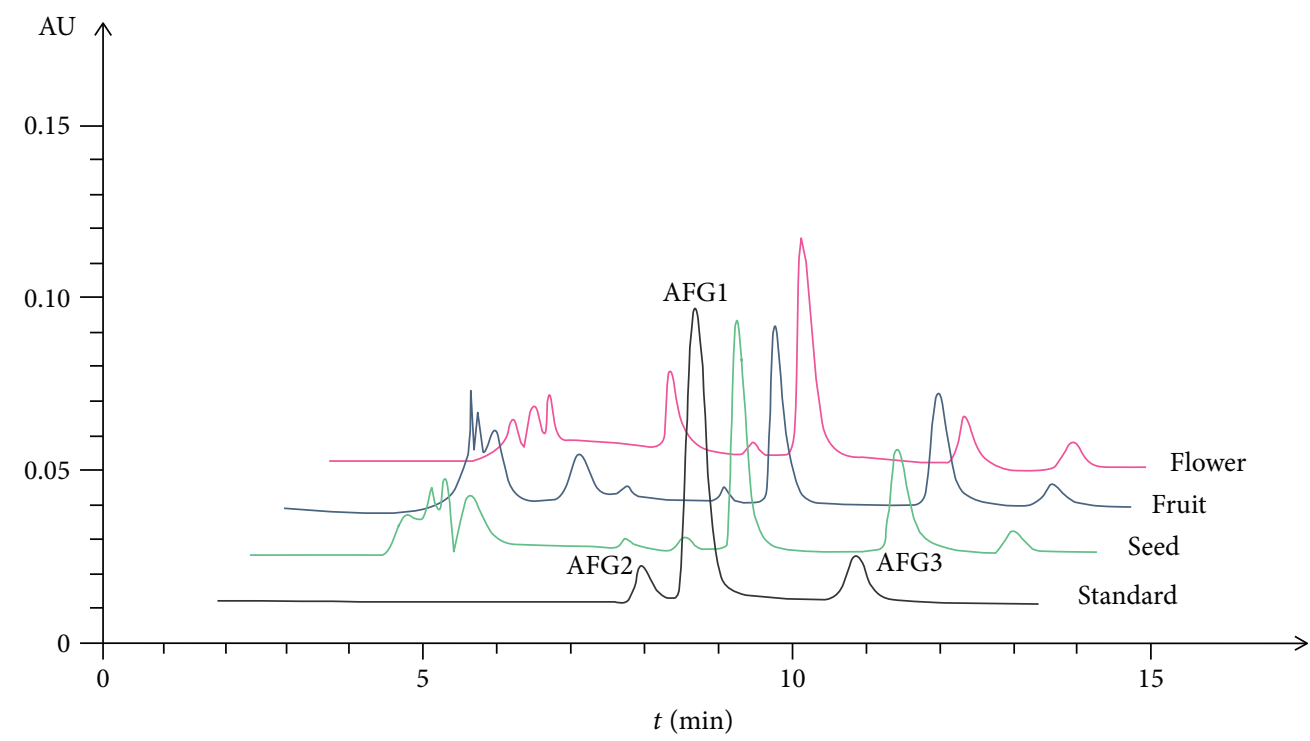

Figure 2: The structures and HPLC chromatogram of AFG-1, AFG-2, and AFG-3 in the flower, fruit, and seed of A. esculentus.

TABLE 2: Effect of AFF on the survival rate and neurologic score in mice subjected to TCI-RI.

\begin{tabular}{lccccc}
\hline Group & Dose $(\mathrm{mg} / \mathrm{kg} / \mathrm{D})$ & $n$ & $n$ (survived mice) & Survival rate (\%) & Neurologic score \\
\hline Normal & 0 & 10 & 10 & 100 & 0 \\
Model & 0 & 19 & 10 & 52.6 & $2.8 \pm 0.79^{\# \#}$ \\
AFF $(300 \mathrm{mg} / \mathrm{kg})$ & 300 & 12 & 10 & 83.3 & $1.2 \pm 0.63^{* *}$ \\
AFF $(150 \mathrm{mg} / \mathrm{kg})$ & 150 & 16 & 10 & 62.5 & $1.5 \pm 0.53^{* *}$ \\
AFF $(75 \mathrm{mg} / \mathrm{kg})$ & 75 & 18 & 10 & 55.5 & $1.9 \pm 0.74^{*}$ \\
\hline
\end{tabular}

Values are mean $\pm \mathrm{SD} .{ }^{*} P<0.05$ and ${ }^{* *} P<0.01$ versus the model group; ${ }^{\#} P<0.01$ versus the normal group.

group, mice in the model group had obvious cerebral infarction $(39.13 \% \pm 1.49)$. Pretreatment with AFF (300 and $150 \mathrm{mg} / \mathrm{kg}$ ) reduced the cerebral infarct area markedly $(P<0.05)$. The results suggested a neuroprotective effect of AFF on TCI-RI mice. After subjection to cerebral ischemia and reperfusion, aerobic respiration gets compromised and the imbalance of $\mathrm{Ca}^{2+}, \mathrm{Na}^{+}$, and ADP ion homeostasis in the nerve cells stimulates the excessive production of mitochondrial oxygen radical [28]. Abnormal production of free radicals increases stress on cellular structures and damages intracellular macromolecules, such as lipids, proteins, and nucleic acids, leading to inactivation of enzymes, destruction of cell membranes, and dysfunction and eventually leading to death of brain tissue cells and excitotoxicity to aggravate the cerebral infarction area [29]. Elevated levels of lipid peroxidation and cytotoxins caused by oxidative stress after ischemia disrupt the tight junctions of endothelial cells, accompanying with increasing permeability of the blood-brain barrier (BBB) and worsening of the infarct severity [30]. Members of the flavonoid family have been 


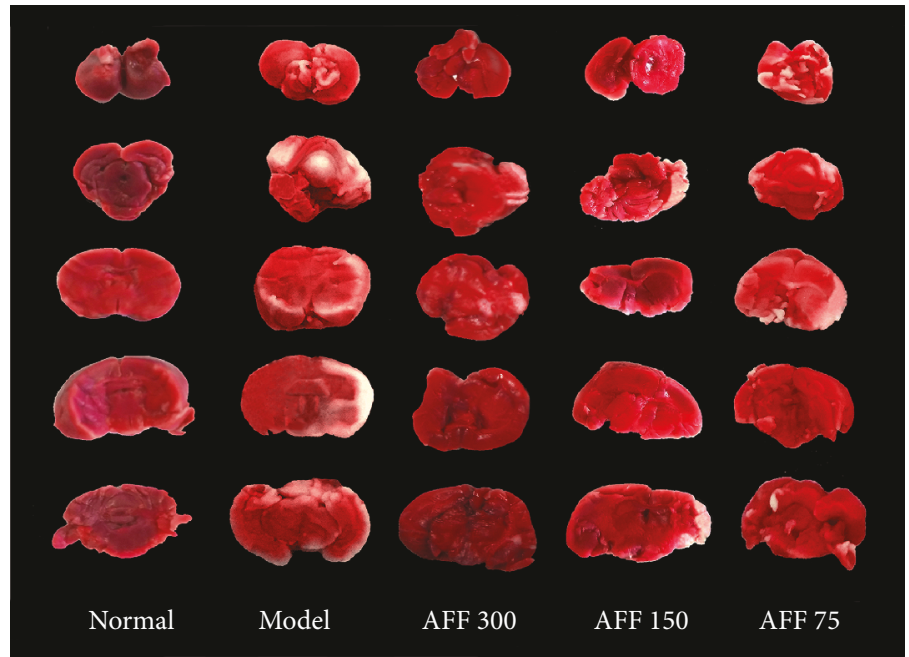

(a)

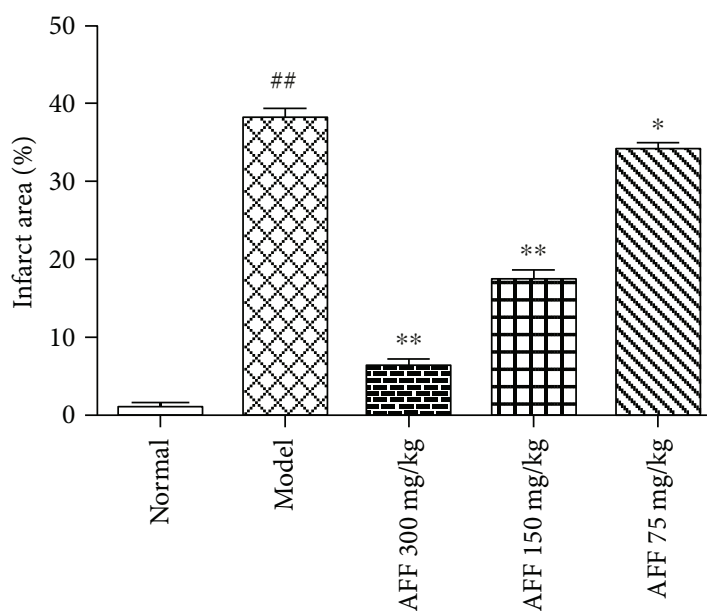

(b)

FIGURE 3: Effect of AFF on infarct areas in mice $\left(n_{1}=3\right)$ after TCI-RI. (a) Representative brain sections of TTC staining. The infarct areas were white. (b) Quantitative results of the infarction area. Values are mean $\pm \mathrm{SD} .{ }^{*} P<0.05$ and ${ }^{* *} P<0.01$ versus the model group; $\# \#<0.01$ versus the normal group.

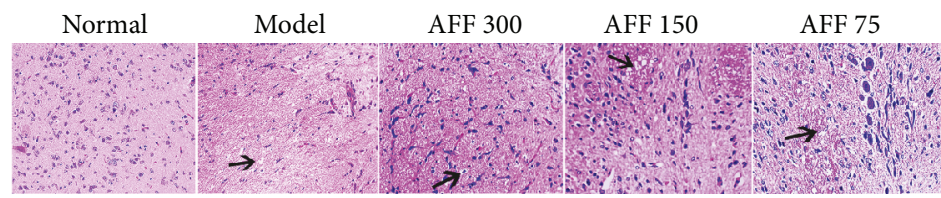

(a)

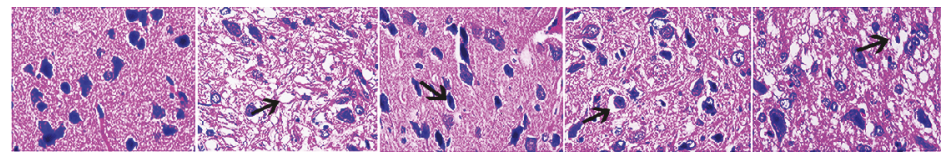

(b)

FIGURE 4: Effects of AFF on cortical area histopathologic changes in the brain of mice $\left(n_{2}=3\right)$ stained with H\&E $(\times 200 ; \times 400)$. (a) HE-stained cerebral cortex of TCI-RI brain $(\times 200)$. (b) HE-stained cerebral cortex of TCI-RI $(\times 400)$. The arrows showed a gradual improvement on cellular edema and atrophic nucleolus.

reported to transverse $\mathrm{BBB}$ [31]. In AFF treatment groups, due to disruption of BBB after the TCI-RI event, AFF accumulated in TCI-RI regions improved neurologic function score and reduced the brain tissue infarct area through antioxidant activity, thereby promoting functional recovery of nerve cells. He et al. had demonstrated that Danhong injection promotes the recovery of neurological function with cerebral infarction by its antioxidant activities [32]. The previous study reported that flavonoids can also improve neurological function and protect brain tissue from cerebral ischemia-reperfusion injury by inhibiting oxidative stress to reduce the damage of the brain microvascular endothelial cell barrier and $\mathrm{BBB}$ function $[6,33]$.

3.4. Histopathology. Transient cerebral ischemia and hypoxia resulted in damage or necrosis of brain tissue accompanied by complex histopathologic changes [34]. Different lesions were observed according to the duration of ischemic insult. Upon ischemia for $30 \mathrm{~min}$, the main damage was to neuronal cells [35]. After the whole brain tissue had been stained with $H \& E$, histopathologic changes were clearly visible (Figures 4(a) and 4(b)). Compared with the normal group, cerebral cortical cells in the model group showed edematous cells, nucleolus atrophy, or cell loss, which were associated with histopathologic changes. Pretreatment with AFF for 7 days prevented neuronal cells from the damage induced by TCI-RI, and the high-dose group had the best effect.

3.5. Effect of the AFF on Cellular Apoptosis Detected by TUNEL Assay. Abnormal formation of reactive oxygen species after reperfusion is one of the major factors inducing apoptosis in neuronal cells [36]. TUNEL 

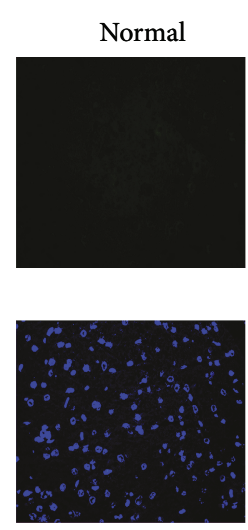

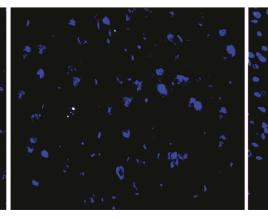

AFF 300

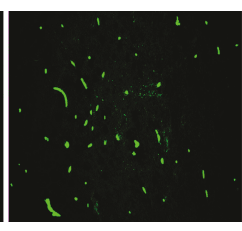

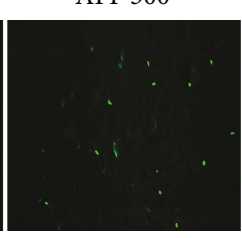

(a)

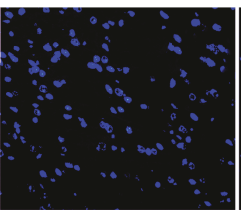

(b)
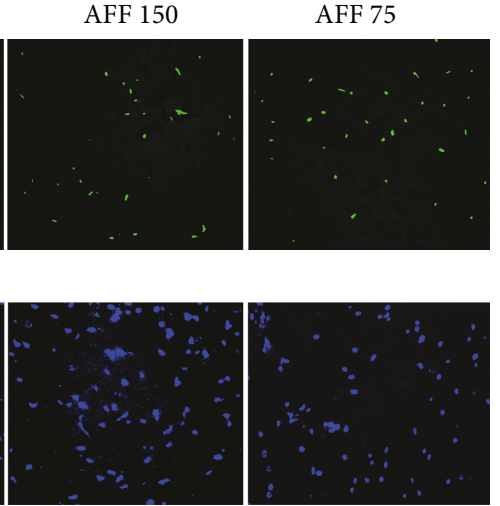

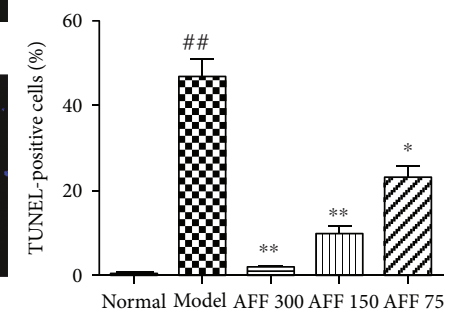

(c)

Figure 5: Effects of AFF on cortical area cellular apoptosis in the brain of mice $\left(n_{2}=3\right)$ with TUNEL assay $(\times 400)$. (a) TUNEL-stained cerebral cortex of TCI-RI brain, the green fluorescence represented the apoptotic cells. (b) DAPI-stained cerebral cortex of TCI-RI. (c) Quantitative data on TUNEL-positive cells in cerebral cortex were obtained. Values are mean \pm SD. \#\# $P<0.01$ versus the normal group; ${ }^{*} P<0.05$ and ${ }^{* *} P<0.01$ versus the model group.

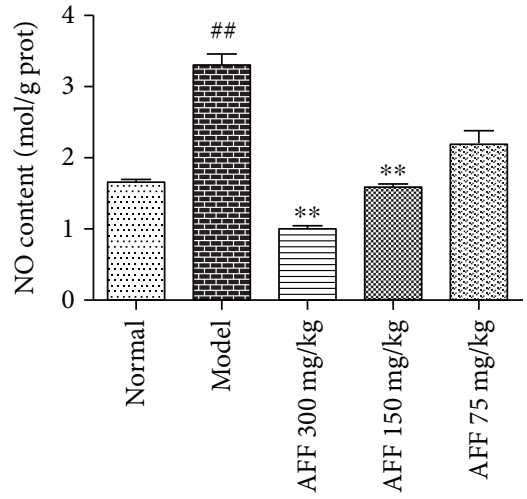

(a)

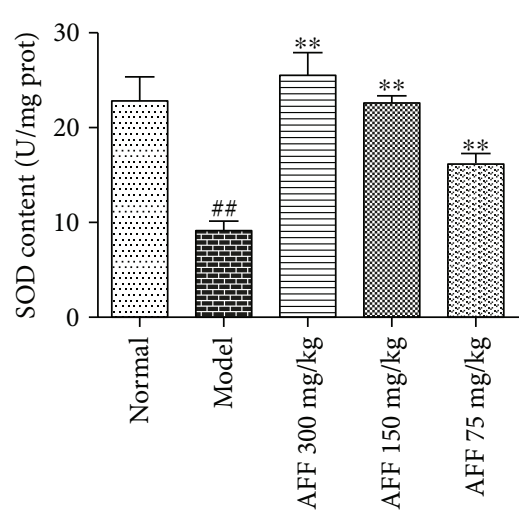

(b)

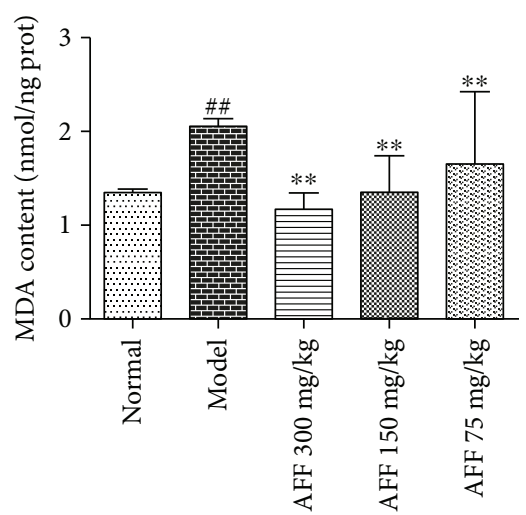

(c)

FIGURE 6: Effects of AFF on NO (a), SOD (b), and MDA (c) content in the brain tissue of mice $\left(\mathrm{n}_{3}=4\right)$ after TCI-RI. Values are mean \pm SD. \#\# $P<0.01$ versus the normal group; ${ }^{* *} P<0.01$ versus the model group.

staining was used to detect apoptotic cells on the basis of DNA fragmentation. The TUNEL-positive cells emitted green fluorescence after fluorescein labeling (Figure 5(a)). The normal group had no TUNEL-positive cells, and apoptotic cells in the model group increased significantly compared with the normal group. After AFF treatment (150 and $300 \mathrm{mg} / \mathrm{kg} \mathrm{BW),} \mathrm{TUNEL-positive} \mathrm{cells} \mathrm{had} \mathrm{sig-}$ nificantly reduced when compared with the model group (Figure 5(c), $P<0.01$ ). AFF had the potential action to protect the brain from TCI-RI damage by decreasing apoptotic cells. Zhang et al. found that pretreatment of flavonoid-rich extract from Rosa laevigata Michx fruit markedly inhibited neuron apoptosis by its antioxidant properties after TCI-RI [37].

3.6. Effect of AFF on the Contents of Protein, NO, SOD, and MDA in Brain Tissue. Several studies have shown that TCIRI can cause severe reperfusion injury and produce a series of cascade reactions: energy depletion, oxidative stress with release of large amounts of free radicals, activation of apoptosis-related genes, calcium overload, release of excitatory neurotransmitters, and inflammation [38]. Oxidative stress is a major cause of secondary injury after TCI-RI. If brain tissue is subjected to ischemic stimulation, oxidative stress causes an imbalance of oxidants and antioxidants in tissue cells and produces excess reactive oxygen species (ROS) [39]. The latter damage the structure and function and inactivate enzymes within mitochondria, resulting in reduced production of adenosine monophosphate (ATP) within them [40]. Intracellular deficiency of ATP reduces the $\mathrm{pH}$, inhibits the activity of $\mathrm{Na}^{+} / \mathrm{Ca}^{2+}$ exchange proteins, increases intracellular levels of $\mathrm{Na}^{+}$and $\mathrm{Ca}^{2+}$, and reduces levels of $\mathrm{K}^{+}$. These ion disorders damage brain cell defense systems, resulting in the apoptosis or death of nerve cells $[6,28] . \mathrm{Ca}^{2+}$ overload increases the expression of nitric oxide synthase (NOS) and $\mathrm{Ca}^{2+}$-dependent proteases. Then, NOS degrades glutamate to produce the nontraditional neurotransmitter NO. Subsequently, xanthine dehydrogenase is 

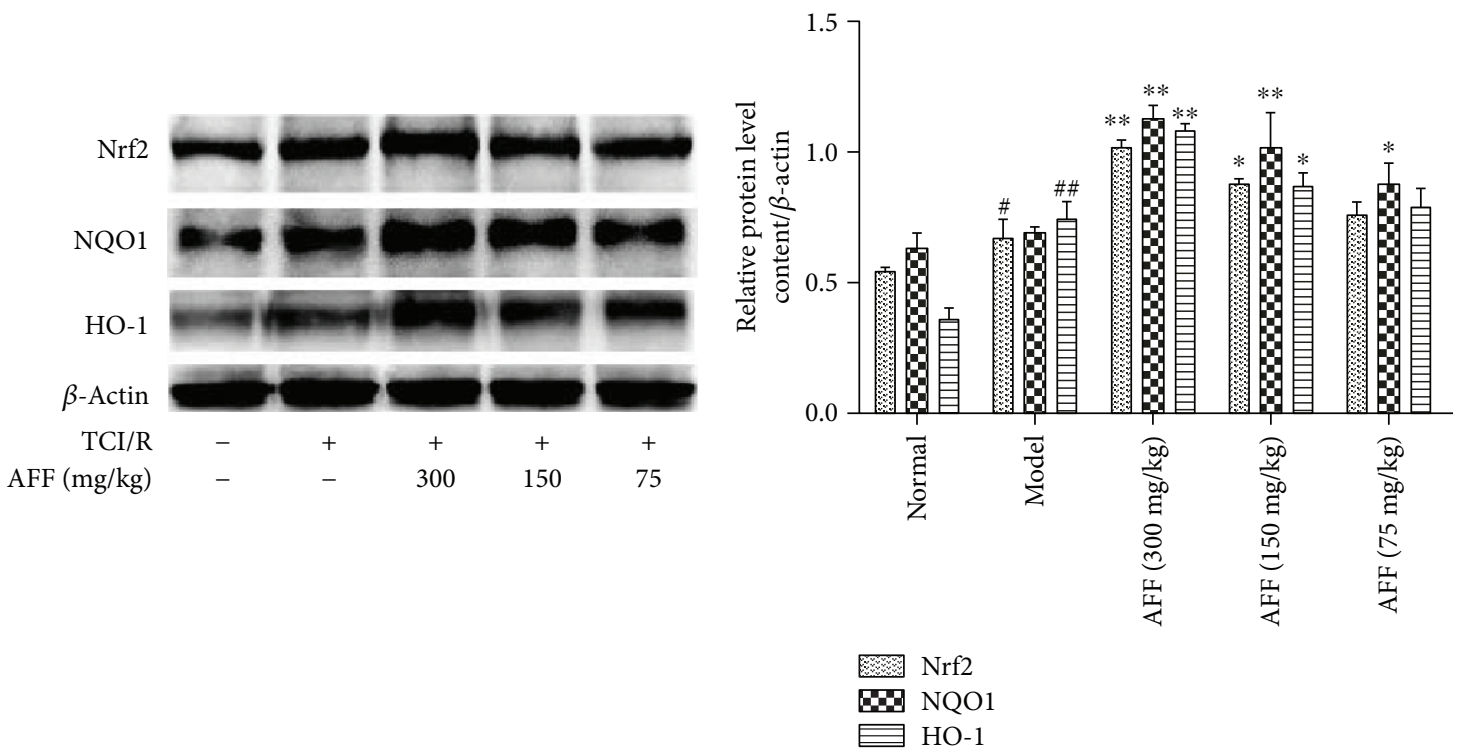

(a)

(b)

FIgURE 7: Effects of AFF on the expression level of Nrf2, NQO1, and HO-1 $\left(n_{3}=4\right)$. (a) The expression levels of Nrf2, NQO1, and HO-1 were analyzed by Western blotting. (b) Quantitative results of the expression levels. Values are mean \pm SD. ${ }^{*} P<0.05$ and ${ }^{* *} P<0.01$ versus the model group; ${ }^{\#} P<0.05$ and ${ }^{\# \# ~} P<0.01$ versus the normal group.

transformed to xanthine oxidase, which increases the levels of $\mathrm{NO}$ and oxygen free radicals $[39,41]$. NO has complex roles in many diseases, including inhibition of mitochondrial function, and has toxic responses to induce cell death $[42,43]$. The determination of the protein concentration in the tissue homogenate supernatant is not of a direct clinical value and used for the calculation of the relative content of other biochemical parameters $[6,37,44]$. The NO content increased markedly in mice of the model group compared with those in the normal group, and it was reduced significantly in AFF groups (300 and $150 \mathrm{mg} / \mathrm{kg}$ ) compared with the model group; these differences were significant (Figure 6(a), $P<0.05$ ).

The enzyme SOD scavenges superoxide anion radicals in vivo and can scavenge ROS, including superoxide anion radicals [45]. Decreased activity of SOD can cause massive accumulation of free radicals in brain tissue, which induces the lipid peroxidation of phospholipids and unsaturated fatty acids in cell membranes [6]. Then, levels of the final product of lipid peroxidation, MDA, increase accordingly, resulting in destruction of the structure and function of cell membranes and damage to neurons $[46,47]$. Due to the scavenging of oxygen free radicals, SOD content is reduced and MDA content is increased after TCI-RI. Therefore, measuring the content of SOD and MDA can, indirectly, reflect the ability of the body to scavenge free radicals and the degree of damage caused by these chemicals [48]. Compared with the normal group, the SOD level in the brain tissue of mice in the model group was reduced significantly by $59.7 \%(P<0.01)$ whereas the MDA content was increased by $51.9 \%$. Pretreatment with AFF protected mice from TCI-RI, and levels of SOD and MDA were increased significantly and decreased, respectively (Figures 6(b) and 6(c), $P<0.01$ ).

3.7. Effect of AFF on the Expression of Nrf2, NQO1, and HO-1. TCI-RI is a very complex pathologic process, so the mechanism is also complex. Several studies have shown that oxidative stress is one of the major causes of TCI-RI. Mechanisms of antioxidant stress include direct scavenging of free radicals as well as indirect antioxidant activity through modulation of the pathways involved in the expression of cytoprotective enzymes and molecules [7]. Chen et al. [49] reported that the extent of scavenging of the DPPH radical of flavonoids in A. esculentus flowers was greater than that of vitamin $C$ at the same concentration. The inducible Nrf2-ARE pathway helps to regulate the expression of phase II-detoxifying and antioxidant enzymes. In a normal physiologic environment, Nrf2 is in the cytoplasm bound to its "natural restrainer," Kelch-like ECH-associated protein 1 (Keap1), which induces the ubiquitination and constitutive degradation of Nrf2. If subjected to oxidative stress, Nrf2 dissociates from Keap1 and moves to the nucleus. Here, it binds to small musculoaponeurotic fibrosarcoma (Maf) protein to form a heterodimer and recognizes the appropriate ARE sequence to promote transcription of the antioxidant genes SOD, HO- 1 , and NQO1 $[8,50-52]$.

Previous studies had demonstrated that total flavonoids have a protective effect on PC12 cells and through PC12 cells; it can be visually seen that Nrf2 is transferred from the cytoplasm to the nucleus when exposed to oxidative stress [53]. Huang et al. [54] found that the addition of HO-1 inhibitors (ZnPP) significantly reduces the protective effect on PC12 cells. Wu et al. [7] showed that 


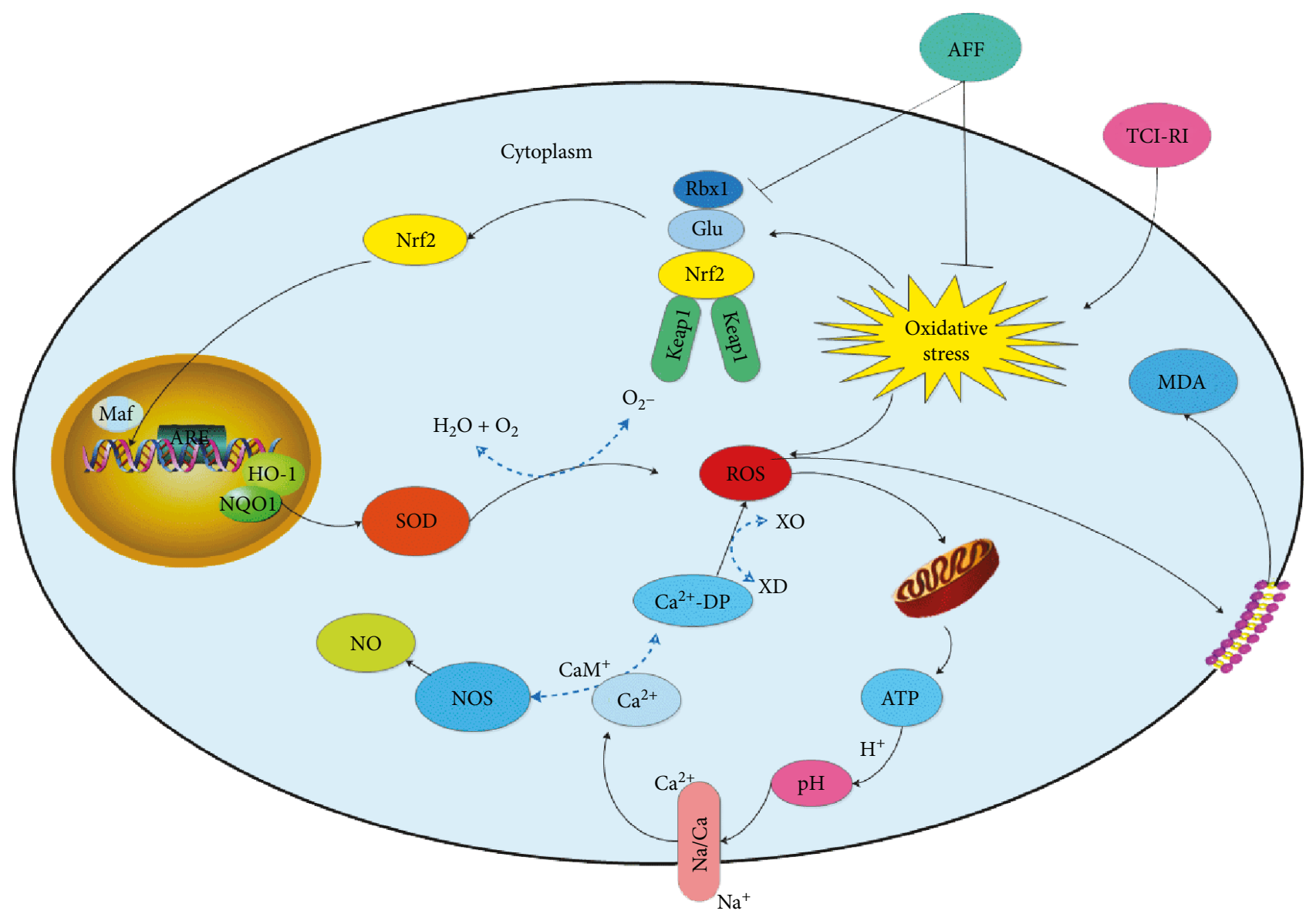

FIGURE 8: Mechanism of TCI-RI and protective effect of AFF on TCI-RI in nerve cells. AFF directly scavenged free radicals and indirectly activated the Nrf2-ARE pathway to enhance the expressions of antioxidase NQO1 and HO-1 and increase SOD content, against oxidative stress, which significantly reduced the content of NO, MDA, and protected TCI-RI.

mice lacking Nrf2 are more susceptible to oxidative stress. Therefore, we investigated if AFF has a neuroprotective role by inducing the Nrf2-ARE pathway in TCI-RI in vivo. Compared with the model group, the expression of Nrf2, NQO1, and HO-1 in AFF-treated mice was upregulated significantly (Figures $7(\mathrm{a})$ and $7(\mathrm{~b}), P<0.01$ ). These results corresponded with the study [8]. Hence, the underlying molecular mechanism of the therapeutic effects of AFF on cerebral ischemic stroke was its antioxidant activity and modulation of the Nrf2-ARE pathway in response to oxidative stress (Figure 8). Nrf2 is a promising therapeutic target for defense against oxidative stress in stroke, and AFF will be an excellent medicine to protect against TCI-RI by activating the Nrf2-ARE pathway.

\section{Conclusions}

Our study demonstrated that AFF had protective effects against TCI-RI possibly by direct (scavenging free radicals) and indirect (activating the neuronal Nrf2-ARE pathway to modulate damage by oxidative stress) actions. This research provides a theoretical basis for the development of AFF as a functional food and its therapeutic effects on ischemic cardiovascular diseases.

\section{Data Availability}

The data used to support the findings of this study are included within the article.

\section{Additional Points}

Chemical Compounds. Rutin (PubChem CID: 5280805), 2,3,5-triphenyltetrazolium chloride (PubChem CID: 9283), and chloral hydrate (PubChem CID: 2707) are the chemical compounds used in the study.

\section{Conflicts of Interest}

The authors have no conflict of interest in this research.

\section{Acknowledgments}

This project is sponsored by Zhejiang Provincial Natural Science Foundation of China (LY13H280011). 


\section{Supplementary Materials}

The corresponding experimental data associated with this article can be seen from the supplementary materials' files. (Supplementary Materials)

\section{References}

[1] J. F. Meschia, C. Bushnell, B. Boden-Albala et al., "Guidelines for the primary prevention of stroke: a statement for healthcare professionals from the American Heart Association/ American Stroke Association," Stroke, vol. 45, no. 12, pp. 3754-3832, 2014.

[2] Y. Yang and H. Sun, "Research progress of acupuncture for cerebral ischemia reperfusion injury in recent 10 years," Zhongguo zhen jiu= Chinese acupuncture \& moxibustion, vol. 35, no. 7, pp. 749-752, 2015.

[3] X. L. Hou, Q. Tong, W. Q. Wang et al., "Suppression of inflammatory responses by dihydromyricetin, a flavonoid from Ampelopsis grossedentata, via inhibiting the activation of NF- $\kappa$ B and MAPK signaling pathways," Journal of Natural Products, vol. 78, no. 7, pp. 1689-1696, 2015.

[4] Y. Gursoy-Ozdemir, A. Can, and T. Dalkara, "Reperfusioninduced oxidative/nitrative injury to neurovascular unit after focal cerebral ischemia," Stroke, vol. 35, no. 6, pp. 14491453, 2004.

[5] H. Pradeep, J. B. Diya, S. Shashikumar, and G. K. Rajanikant, "Oxidative stress - assassin behind the ischemic stroke," Folia Neuropathologica, vol. 50, no. 3, pp. 219-230, 2012.

[6] Y. Liu, L. Zhang, and J. Liang, "Activation of the Nrf2 defense pathway contributes to neuroprotective effects of phloretin on oxidative stress injury after cerebral ischemia/reperfusion in rats," Journal of the Neurological Sciences, vol. 351, no. 1-2, pp. 88-92, 2015.

[7] G. Wu, L. Zhu, X. Yuan et al., "Britanin ameliorates cerebral ischemia-reperfusion injury by inducing the Nrf2 protective pathway," Antioxidants \& Redox Signaling, vol. 27, no. 11, pp. 754-768, 2017.

[8] R. Zhang, M. Xu, Y. Wang, F. Xie, G. Zhang, and X. Qin, "Nrf2-a promising therapeutic target for defensing against oxidative stress in stroke," Molecular Neurobiology, vol. 54, no. 8, pp. 6006-6017, 2016.

[9] P. Arapitsas, "Identification and quantification of polyphenolic compounds from okra seeds and skins," Food Chemistry, vol. 110, no. 4, pp. 1041-1045, 2008.

[10] H. Al-Wandawi, "Chemical composition of seeds of two okra cultivars," Journal of Agricultural and Food Chemistry, vol. 31, no. 6, pp. 1355-1358, 1983.

[11] S. C. Sheu and M. H. Lai, "Composition analysis and immunomodulatory effect of okra (Abelmoschus esculentus L.) extract," Food Chemistry, vol. 134, no. 4, pp. 1906-1911, 2012.

[12] Y. Okada, M. Okada, and Y. Sagesaka, "Screening of dried plant seed extracts for adiponectin production activity and tumor necrosis factor-alpha inhibitory activity on 3T3-L1 adipocytes," Plant Foods for Human Nutrition, vol. 65, no. 3, pp. 225-232, 2010.

[13] K. Panneerselvam, S. Ramachandran, V. Sabitha, and K. R. Naveen, "Antidiabetic and antihyperlipidemic potential of Abelmoschus esculentus (L.) Moench. in streptozotocininduced diabetic rats," Journal of Pharmacy and Bioallied Sciences, vol. 3, no. 3, pp. 397-402, 2011.
[14] O. J. Oyelade, B. I. O. Ade-Omowaye, and V. F. Adeomi, "Influence of variety on protein, fat contents and some physical characteristics of okra seeds," Journal of Food Engineering, vol. 57, no. 2, pp. 111-114, 2003.

[15] W. Zheng, T. Zhao, W. Feng et al., "Purification, characterization and immunomodulating activity of a polysaccharide from flowers of Abelmoschus esculentus," Carbohydrate Polymers, vol. 106, pp. 335-342, 2014.

[16] Y. Lin, M. F. Lu, H. B. Liao, Y. X. Li, W. Han, and K. Yuan, "Content determination of the flavonoids in the different parts and different species of Abelmoschus esculentus L. by reversed phase-high performance liquid chromatograph and colorimetric method," Pharmacognosy Magazine, vol. 10, no. 39, pp. 278-284, 2014.

[17] A. Akrout, L. A. Gonzalez, H. El Jani, and P. C. Madrid, “Antioxidant and antitumor activities of Artemisia campestris and Thymelaea hirsuta from southern Tunisia," Food and Chemical Toxicology, vol. 49, no. 2, pp. 342-347, 2011.

[18] G. Ai, Q. Liu, W. Hua, Z. Huang, and D. Wang, "Hepatoprotective evaluation of the total flavonoids extracted from flowers of Abelmoschus manihot (L.) Medic: in vitro and in vivo studies," Journal of Ethnopharmacology, vol. 146, no. 3, pp. 794-802, 2013.

[19] E. Z. Longa, P. R. Weinstein, S. Carlson, and R. Cummins, "Reversible middle cerebral artery occlusion without craniectomy in rats," Stroke, vol. 20, no. 1, pp. 84-91, 1989.

[20] L. Gao, D. Liu, and L. Xu, "Research progress and prospects of okra," Chinese Journal of Tropical Agriculture, vol. 34, pp. 2229, 2014.

[21] A. Ahmad, M. M. Khan, S. S. Raza et al., "Ocimum sanctum attenuates oxidative damage and neurological deficits following focal cerebral ischemia/reperfusion injury in rats," Neurological Sciences, vol. 33, no. 6, pp. 1239-1247, 2012.

[22] J. Cao, X. Xia, X. Chen, J. Xiao, and Q. Wang, "Characterization of flavonoids from Dryopteris erythrosora and evaluation of their antioxidant, anticancer and acetylcholinesterase inhibition activities," Food and Chemical Toxicology, vol. 51, pp. 242-250, 2013.

[23] K. Yuan, H. Liao, W. Dong, X. Shi, and H. Liu, "Analysis and comparison of the active components and antioxidant activities of extracts from Abelmoschus esculentus L," Pharmacognosy Magazine, vol. 8, no. 30, pp. 156-161, 2012.

[24] B. Halliwell, "Reactive oxygen species and the central nervous system," Journal of Neurochemistry, vol. 59, no. 5, pp. 16091623, 1992.

[25] H. Y. Meng, "New clinical development of transient ischemic attacks," Chinese Journal of Coal Industry Medicine, vol. 3, pp. 487-488, 2010.

[26] M. Miao, X. Yan, L. Guo, and S. Shao, "Effects of the Rabdosia rubescens total flavonoids on focal cerebral ischemia reperfusion model in rats," Saudi Pharmaceutical Journal, vol. 25, no. 4, pp. 607-614, 2017.

[27] R. Tsuchidate, Q.-P. He, M.-L. Smith, and B. K. Siesjö, "Regional cerebral blood flow during and after 2 hours of middle cerebral artery occlusion in the rat," Journal of Cerebral Blood Flow \& Metabolism, vol. 17, no. 10, pp. 1066-1073, 1997.

[28] Y. C. Zhang, F. F. Gan, S. B. Shelar, K. Y. Ng, and E. H. Chew, "Antioxidant and Nrf2 inducing activities of luteolin, a flavonoid constituent in Ixeris sonchifolia Hance, provide 
neuroprotective effects against ischemia-induced cellular injury," Food and Chemical Toxicology, vol. 59, pp. 272-280, 2013.

[29] L. S. Zhang, J. J. Li, and C. Y. Wu, "Research progress of injury mechanism and related signal pathways of cerebral ischemia," Chinese Journal of Neuroanatomy, vol. 30, pp. 729-732, 2014.

[30] X. K. Tu, W. Z. Yang, R. S. Liang et al., "Effect of baicalin on matrix metalloproteinase- 9 expression and blood-brain barrier permeability following focal cerebral ischemia in rats," Neurochemical Research, vol. 36, no. 11, pp. 2022-2028, 2011.

[31] K. A. Youdim, M. S. Dobbie, G. Kuhnle, A. R. Proteggente, N. J. Abbott, and C. Rice-Evans, "Interaction between flavonoids and the blood-brain barrier: in vitro studies," Journal of Neurochemistry, vol. 85, no. 1, pp. 180-192, 2003.

[32] Y. He, H. Wan, Y. du et al., "Protective effect of Danhong injection on cerebral ischemia-reperfusion injury in rats," Journal of Ethnopharmacology, vol. 144, no. 2, pp. 387-394, 2012.

[33] A. Üllen, G. Fauler, E. Bernhart et al., "Phloretin ameliorates 2chlorohexadecanal-mediated brain microvascular endothelial cell dysfunction in vitro," Free Radical Biology and Medicine, vol. 53, no. 9, pp. 1770-1781, 2012.

[34] C. C. Wang, R. Liu, S. H. Yuan, Q. X. Liu, and J. B. Chen, “The role of CXCL12 on the ultra-early time of transient focal brain ischemic injury in rats," Journal of Apoplexy and Neurological Diseases, vol. 12, pp. 1095-1098, 2015.

[35] Y. J. Wang, W. W. He, and Q. E. Lang, "Pathological changes of brain tissue after cerebral ischemia," Progress of Anatomical Sciences, vol. 3, pp. 264-270, 1995.

[36] I. Olmez and H. Ozyurt, "Reactive oxygen species and ischemic cerebrovascular disease," Neurochemistry International, vol. 60, no. 2, pp. 208-212, 2012.

[37] S. Zhang, Y. Qi, Y. Xu et al., "Protective effect of flavonoidrich extract from Rosa laevigata Michx on cerebral ischemia-reperfusion injury through suppression of apoptosis and inflammation," Neurochemistry International, vol. 63, no. 5, pp. 522-532, 2013.

[38] N. Cho, J. H. Choi, H. Yang et al., "Neuroprotective and antiinflammatory effects of flavonoids isolated from Rhus verniciflua in neuronal HT22 and microglial BV2 cell lines," Food and Chemical Toxicology, vol. 50, no. 6, pp. 1940-1945, 2012.

[39] M. J. O’Neill, T. K. Murray, D. R. McCarty et al., “ARL 17477, a selective nitric oxide synthase inhibitor, with neuroprotective effects in animal models of global and focal cerebral ischaemia," Brain Research, vol. 871, no. 2, pp. 234-244, 2000.

[40] M. F. Anderson and N. R. Sims, "The effects of focal ischemia and reperfusion on the glutathione content of mitochondria from rat brain subregions," Journal of Neurochemistry, vol. 81, no. 3, pp. 541-549, 2002.

[41] Y. Chen, T. Chen, and H. Feng, "Present situation of injury mechanism and treatment of cerebral ischemia reperfusion," Medical Research Education, vol. 6, pp. 47-54, 2012.

[42] S. Ashwal, D. J. Cole, S. Osborne, T. N. Osborne, and W. J. Pearce, "L-NAME reduces infarct volume in a filament model of transient middle cerebral artery occlusion in the rat pup," Pediatric Research, vol. 38, no. 5, pp. 652-656, 1995.

[43] M. Ozaki, S. Kawashima, T. Hirase et al., "Overexpression of endothelial nitric oxide synthase in endothelial cells is protective against ischemia-reperfusion injury in mouse skeletal muscle," The American Journal of Pathology, vol. 160, no. 4, pp. 1335-1344, 2002.

[44] N. X. Zhang, J. Q. Yi, L. Y. Feng, X. P. Gong, and Y. F. Sun, "Study on the determination of protein content in tissue homogenate supernatant," Hebei Medical Journal, vol. 5, pp. 408-409, 1999.

[45] H. J. Wang, Y. Y. Jiang, P. Lu, Q. Wang, and T. Ikejima, “An updated review at molecular pharmacological level for the mechanism of anti-tumor, antioxidant and immunoregulatory action of silibinin," Yao Xue Xue Bao, vol. 45, no. 4, pp. 413$421,2010$.

[46] Y. Zhao, L. D. Lu, and X. H. Zhen, "Effect of chuanxiong polysaccharide on cerebral ischemia and reperfusion injury and expression of high mobility group box protein B1 in rats," Chinese Journal of Gerontology, vol. 37, pp. 2878-2880, 2017.

[47] I. M. Cojocaru, M. Cojocaru, V. Sapira, and A. Ionescu, "Evaluation of oxidative stress in patients with acute ischemic stroke," Romanian journal of internal medicine $=$ Revue roumaine de medecine interne, vol. 51, no. 2, pp. 97-106, 2013.

[48] D. S. Warner, H. Sheng, and I. Batinić-Haberle, "Oxidants, antioxidants and the ischemic brain," Journal of Experimental Biology, vol. 207, no. 18, pp. 3221-3231, 2004.

[49] B. Chen, Z. Ma, and Y. Sun, "Analysis of extraction and antioxidant of flavonoids in Abelmoschus esculents L. flower," Jiangsu Condiment and Subsidiary Food, vol. 3, pp. 20-23, 2017.

[50] K. Itoh, N. Wakabayashi, Y. Katoh, T. Ishii, T. O'Connor, and M. Yamamoto, "Keap1 regulates both cytoplasmicnuclear shuttling and degradation of Nrf2 in response to electrophiles," Genes to Cells, vol. 8, no. 4, pp. 379-391, 2003.

[51] M. Kobayashi and M. Yamamoto, "Nrf2-Keap1 regulation of cellular defense mechanisms against electrophiles and reactive oxygen species," Advances in Enzyme Regulation, vol. 46, no. 1, pp. 113-140, 2006.

[52] S. K. Niture, R. Khatri, and A. K. Jaiswal, "Regulation of Nrf2 - an update," Free Radical Biology and Medicine, vol. 66, pp. 36-44, 2014.

[53] M. Liu, Y. Xu, X. Han et al., "Potent effects of flavonoid-rich extract from Rosa laevigata Michx fruit against hydrogen peroxide-induced damage in PC12 cells via attenuation of oxidative stress, inflammation and apoptosis," Molecules, vol. 19, no. 8, pp. 11816-11832, 2014.

[54] L. Huang, J. Wang, L. Chen et al., "Design, synthesis, and evaluation of NDGA analogues as potential anti-ischemic stroke agents," European Journal of Medicinal Chemistry, vol. 143, pp. 1165-1173, 2018. 


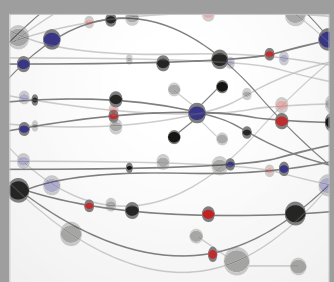

The Scientific World Journal
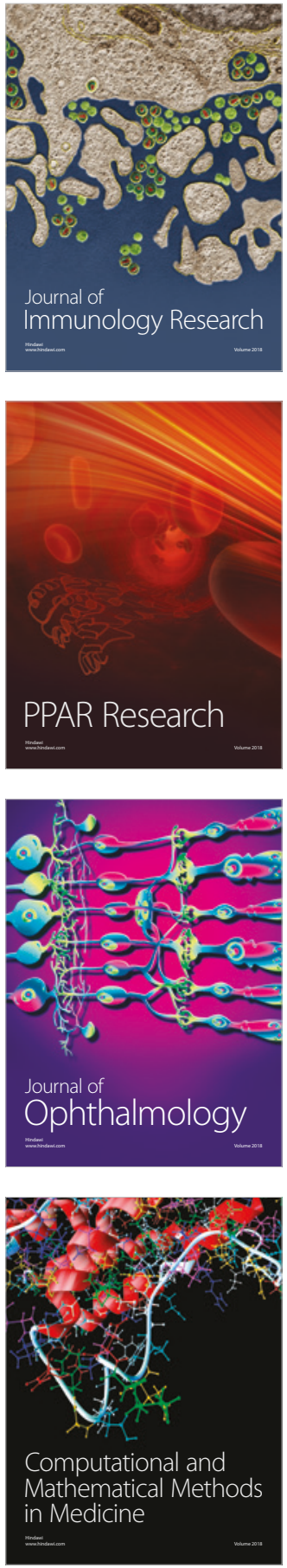

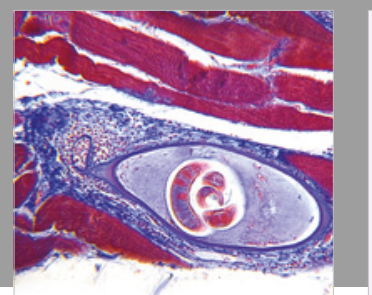

Gastroenterology Research and Practice

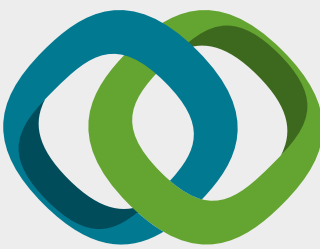

\section{Hindawi}

Submit your manuscripts at

www.hindawi.com
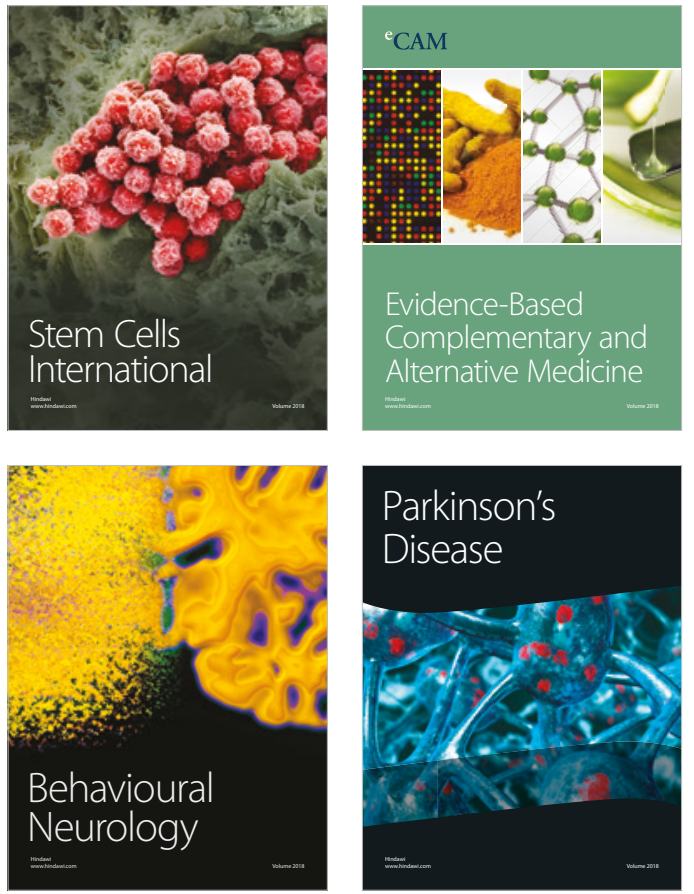

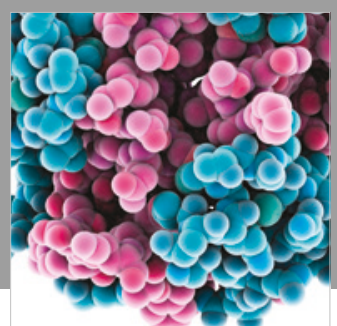

ournal of

Diabetes Research

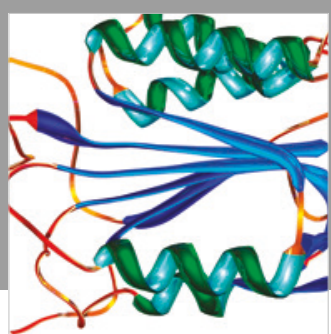

Disease Markers
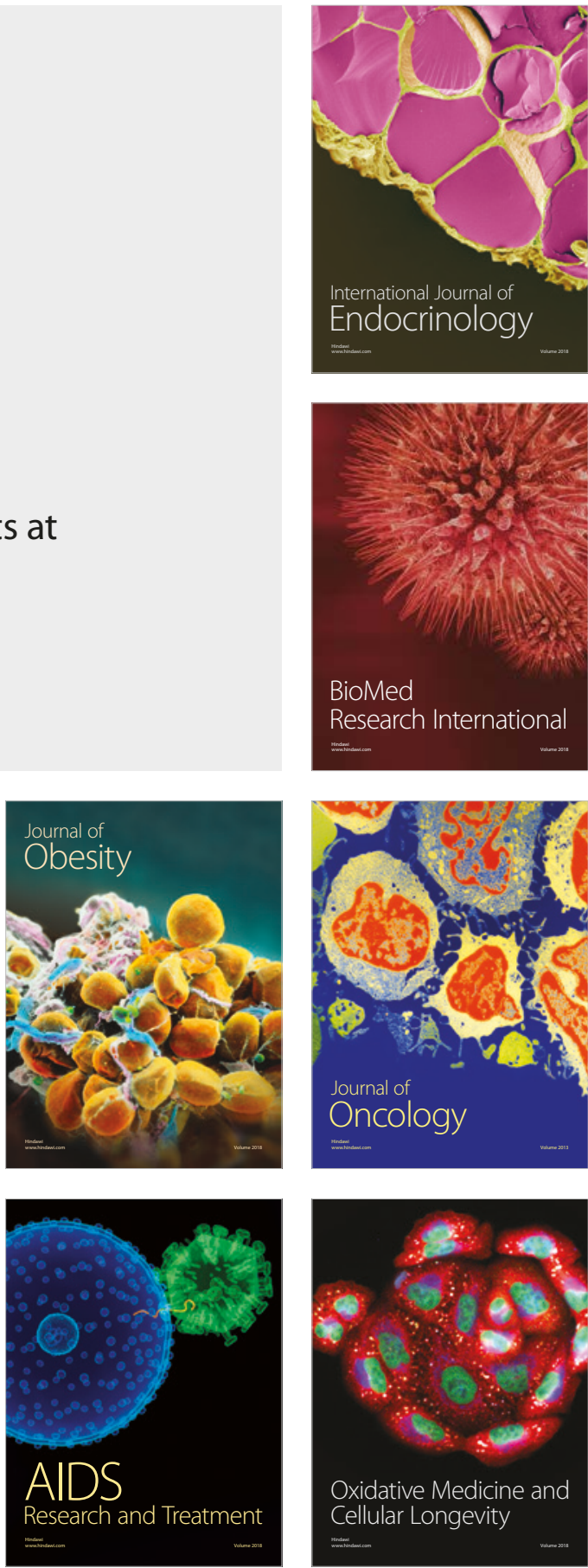